\title{
Emergence Patterns of the Seedcorn Maggot, Delia platura (Diptera: Anthomyiidae)
}

\author{
JAMES E. THRONE ${ }^{1}$ AND C. J. ECKENRODE ${ }^{2}$ \\ Department of Entomology, New York State Agricultural Experiment Station, \\ Cornell University, Geneva, New York 14456
}

\begin{abstract}
Environ. Entomol. 14: 182-186 (1985)
ABSTRACT Time of emergence of seedcorn maggot (SCM), Delia platura (Meigen), adults that developed from eggs laid in field plots from May through October 1981, was determined during 1981, 1982, and 1983. Some SCM that developed from eggs laid as early as May 1981, overwintered, and the proportion of SCM overwintering increased when eggs were laid June to October. Adults emerged from overwintered pupae from April through October 1982, and in May and June 1983. Adults of the closely related bean seed maggot (BSM), $D$. florilega (Zetterstedt), also emerged in the plots, but in smaller numbers than SCM. BSM males emerged in 1981 only in plots planted during May 1981.
\end{abstract}

SEedCoRn MagGots (SCM), Delia platura (Meigen), are cosmopolitan pests of many crops (Throne 1980). In New York State, SCM larvae can be found in small numbers on many newly seeded crops throughout the growing season, and the larvae damage germinating seeds and seedlings (Vea et al. 1975). Occasionally, the damage is extensive enough that yield is reduced (Vea and Eckenrode 1976) or entire fields require reseeding. Many growers treat seed of susceptible crops with insecticide before planting, thereby protecting the plants from attack by SCM during the vulnerable period of germination to emergence of seedlings.

In New York State, significant damage occurs only during a 1-or 2-week period during and following SCM flight peaks, as monitored with baited cone traps (Eckenrode and Chapman 1971). Control of SCM is necessary during this period. If growers were forewarned of impending flight peaks, they could restrict the use of insecticidetreated seed to periods when the probability of damage was high; or, when possible, they could avoid planting during these periods, thereby avoiding serious SCM damage.

Flight peaks of the closely related cabbage maggot, $D$. radicum (L.), and onion maggot, D. antiqua (Meigen), have been correlated with heat unit accumulations-i.e., degree days (Eckenrode and Chapman 1972) or thermal unit accumulations (Eckenrode et al. 1975). SCM flight peaks have been correlated with heat unit accumulations in Wisconsin (Strong and Apple 1958) and in Iowa (Funderburk et al. 1984). However, attempts at correlating SCM flight peaks with heat unit accumulations in New York State have been unsuccessful (unpublished data). Therefore, a computer model for simulating SCM development was de-

\footnotetext{
${ }^{1}$ Present address: Dept. of Entomology, North Carolina State Univ., 840 Method Rd., Unit 2, Box 7628, Raleigh, NC 276957628 .

${ }^{2}$ To whom reprint requests should be addressed.
}

veloped to try to predict SCM flight peaks (Throne 1983). However, determination of the pattern of development of SCM in the field was required before the model could be validated. The objective of the present study was to monitor development of SCM in the field with emergence traps.

\section{Materials and Methods}

Emergence traps were used to determine times of emergence of SCM adults in 1981, 1982, and 1983 from pupae developing in bean plots planted in Geneva, N.Y., during 1981. An area ( 57 by 39 $\mathrm{m}$ ) was cultivated and divided into 54 plots $\left(1 \mathrm{~m}^{2}\right)$ during April 1981. Plots were separated on all sides by 1 -m walkways. Every 7 days from 4 May to 31 August 1981, the soil in three randomly chosen plots was cultivated with a hoe, and ca. $100 \mathrm{~g}$ of 'Bush Blue Lake 47' snap beans, Phaseolus vulgaris L., were planted in a $0.5-\mathrm{m}$ diameter, circular area in the center of each of the three plotsi.e., three replications per week. The seeds were covered with ca. $0.5 \mathrm{~cm}$ of soil, and ca. $100 \mathrm{~g}$ of meat and bone meal and 1 liter of water were poured over the soil in the planted areas to attract flies for oviposition (Eckenrode and Chapman 1971). On the same day, a 1-m row of beans was planted on either side of the circular area in each plot to simulate the microclimate in a bean field. An adjacent area was cultivated in early September; three additional plots were planted on both 16 September and 14 October.

After allowing 1 week for oviposition by feral flies, the circular area of beans in each of the three plots was covered with a cone trap. A circular trench, ca. $5 \mathrm{~cm}$ deep, was dug in the soil around the beans, the base of the trap was placed in the trench, and soil was packed around the base of the trap. The standard cone trap design (Eckenrode and Chapman 1971) was modified for use as an emergence trap (Throne et al. 1984). 

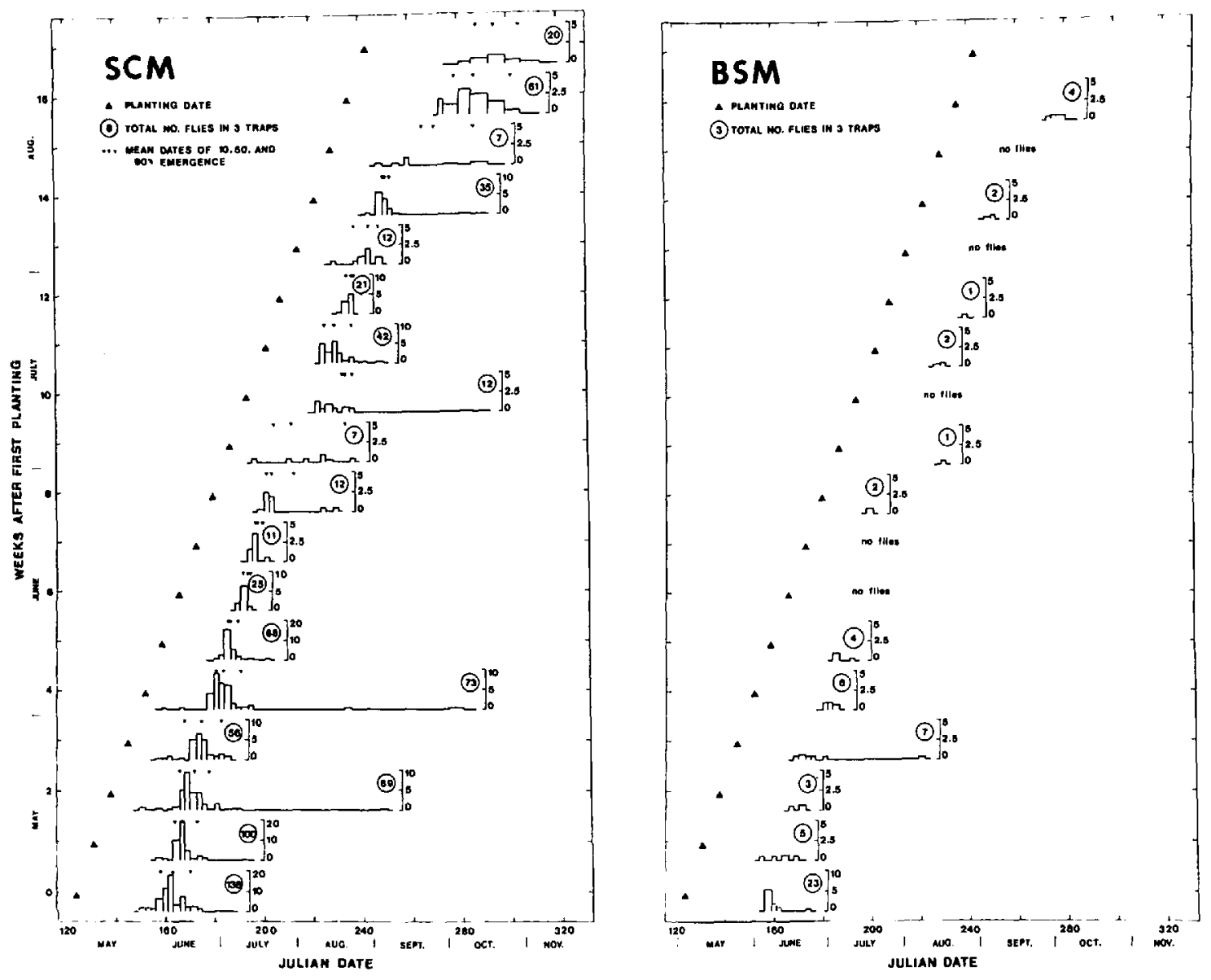

Fig. 1. Emergence of SCM (left) and (right) BSM in 1981 from bean plots planted once each week from May through August 1981, Geneva, N.Y. (3 plots planted per week). The width of a bar indicates the length of the sampling period and, samples were collected less frequently after Julian date 275 . The height of a bar indicates the number of flies emerged in three traps during a sampling period/duration of the sampling.period (i.e., no. flies in three traps per day).

In 1981, the traps were checked for newly emerged flies three times each week until 2 October and then once each week through the winter. Beginning 14 April 1982 , the traps were again checked for newly emerged flies three times each week until 23 July and then once each week until 25 October. In 1983, the traps were checked for newly emerged flies once each week during March and April, and then twice each week during May and June, after which the study was terminated. Flies were killed by squirting a few milliliters of chloroform onto a tissue inserted into the collecting jar. The flies were sexed and identified using keys from Brooks (1951) and Huckett (1971).

We assumed that flies emerging in the traps had developed from eggs laid in the baited areas during the week between planting and placement of the trap. No unbaited plots were covered with a trap to quantify the natural SCM population in the field. However, in previous field experiments, natural SCM populations in unplanted fields containing minimal organic debris were very low. The interior of each trap was visually inspected for flies on each sampling date, and any flies not in the collecting jars were manually removed from the traps. Therefore, no flies remained in the traps more than two to three days during most of the growing season, and we assumed that no breeding occurred in the cages because the preoviposition period for SCM lasts 5 to 20 days at 13 to $33^{\circ} \mathrm{C}$ (Harukawa et al. 1934, Ristich 1950, Yatom 1961).

An analysis of variance was used for statistical comparisons $(\alpha=0.05)$.

\section{Results}

SCM ( $n=770$ ) emerged in the 60 traps during 1981, 284 emerged during 1982, and 35 emerged during 1983. In addition to SCM, 60 bean seed maggot (BSM), D. florilega (Zetterstedt), emerged 


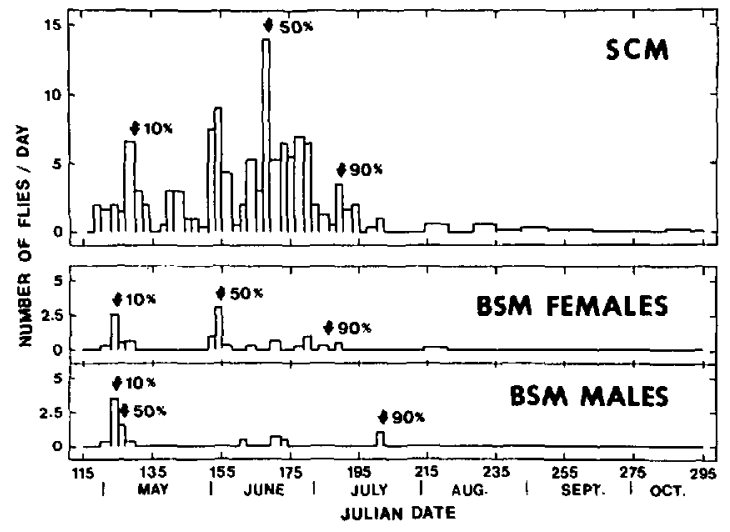

Fig. 2. Emergence of SCM and BSM from overwintered pupae in bean plots, Geneva, N.Y., 1982. Dates of 10,50 , and $90 \%$ emergences are indicated. The width of a bar indicates the length of the sampling period and that samples were collected less frequently after Julian date 204. The height of a bar indicates the number of flies emerged in all 60 traps during a sampling period/ duration of the sampling period (i.e., no. flies in 60 traps per day).

during 1981, 45 emerged during 1982, and 6 emerged during 1983. Field studies on SCM usually include accidental or intentional observations on the closely related BSM because the two species commonly occur together in North America and are difficult to differentiate. In North America, the two species collectively are referred to as the "seed maggot complex." Emergence patterns of BSM are reported here to add to the limited information available on the biology of this pest (Throne 1980).

SCM Emergence. Only 1 SCM emerged in 1981 from plots planted on 16 September, and no SCM emerged in 1981 from plots planted on 14 October. Patterns of emergence of SCM in 1981, from plots planted May through August 1981, are shown in Fig. 1. Females comprised 69\% of the 1981 flies. Differences between the sexes in mean time to $50 \%$ emergence were not statistically significant. Four flies that emerged in 1981 from plots planted 18 May, 1 June, and 13 July emerged after an unusually long time.

Twenty-six percent of SCM emerged the following year (1982). Females comprised $64 \%$ of the newly emerged flies in 1982, and the pattern of emergence was similar for both sexes. Dates of 10 , 50 , and $90 \%$ emergences were 12 May, 18 June, and 5 July for males; 10 May, 14 June, and 12 July for females; and 10 May, 18 June, and 9 July for the sexes combined (Fig. 2), respectively. Dates of emergence were not highly correlated with planting dates the previous summer $(R=0.061$ for males, -0.162 for females, and -0.079 for the sexes combined).

Three percent of SCM emerged in 1983, ca. 2 years after the plots were last uncovered. Dates of 10,50 , and $90 \%$ emergences were 6 May, 27 May,

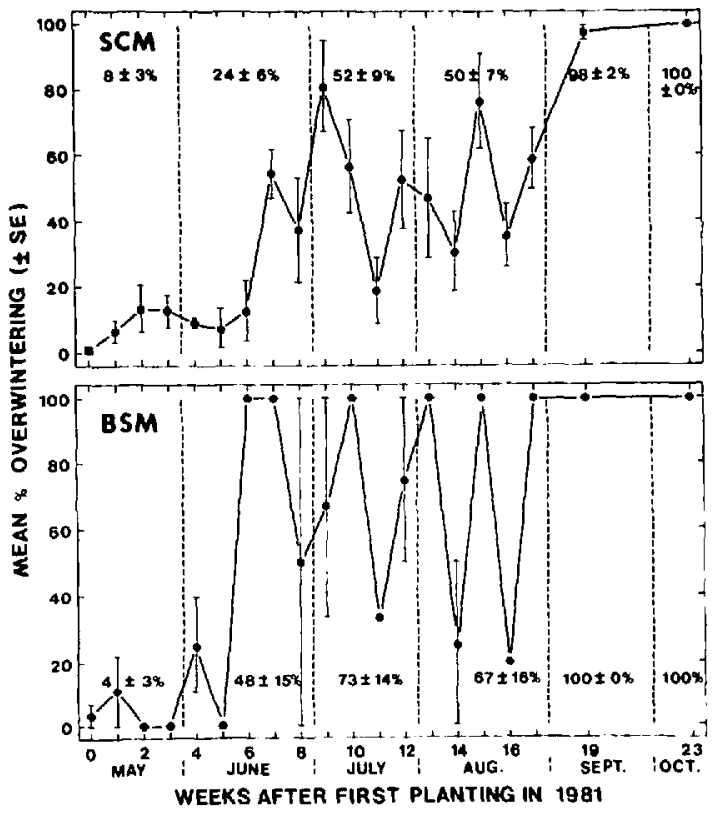

Fig. 3. Percentage overwintering SCM and BSM in bean plots, Geneva, N.Y., 1981 to 1983 (three plots planted per week).

and 27 June, respectively. Females comprised $69 \%$ of 1983 SCM. Dates of emergence in 1983 were not highly correlated with planting dates in 1981 $(r=-0.046)$.

All SCM emerging during 1982 and 1983 were assumed to have diapaused and resulted from oviposition during the time that plots were uncovered. Some of these SCM may have undergone aestivo-hibernation; that is, they may have aestivated during the summer and then diapaused during the winter (Masaki 1980). Percentage of overwintering SCM (approximated by the number of flies emerged in a trap in 1982 and 1983/total number of flies emerged in the trap in 1981, 1982, and 1983) increased as the season progressed in 1981 (Fig. 3). Differences between sexes in percentage overwintering were not statistically significant.

BSM Emergence. No BSM emerged in 1981 from plots planted in September and October 1981. Patterns of emergence of BSM in 1981, from plots planted May through August 1981, are shown in Fig. 1. Only 12 males emerged in 1981 ( $20 \%$ of total BSM in 1981), all from plots planted during May 1981. Females comprised $71 \%$ of the May catch. One female that emerged in 1981 from a plot planted on 25 May emerged after an unusually long time.

Forty-one percent of BSM emerged the following year (1982). Females comprised 60\% of the newly emerged flies in 1982. Dates of 10,50, and $90 \%$ emergences were 5 May, 7 May, and 21 July for males (Fig. 2); 5 May, 4 June, and 4 July for 
females; and 5 May, 2 June, and 4 July for the sexes combined, respectively. All males emerging during 1982 were from plots planted on 22 June 1981 , or later. Dates of emergence were negatively correlated with planting date the previous summer $\langle r=-0.933$ for males, -0.653 for females, and -0.734 for the sexes combined)-i.e., the first flies to emerge in 1982 were from the last plots planted in 1981. Again, some BSM that overwintered may have undergone aestivo-hibernation. The percentage of overwintering BSM for each week of oviposition in 1981 is shown in Fig. 3. The six BSM that emerged in the traps in 1983 were females, and they emerged during May and June.

\section{Diseussion}

Seed maggots may undergo a period of aestivation during the summer. Harris et al. (1966) suggested that at temperatures above $24^{\circ} \mathrm{C}$ all SCM and BSM aestivate. In the present study, $<1 \%$ of SCM and $\angle 2 \%$ of BSM emerged in 1981 after unusually long periods of time, which suggests that these flies aestivated and then emerged the same year. In addition, some or all of the overwintering individuals that developed from eggs laid May through August 1981, may have aestivated before entering diapause. Funderburk et al. (1984) reported that most second generation SCM may aestivate in Iowa.

Miller and McClanahan (1960) reported that all seed maggot adults emerging in the spring in Ontario, Canada, had developed from eggs laid 16 August or later the previous year. The present study shows that overwintering individuals begin to enter hibernation (either diapause or aestivo-hibernation) much earlier in New York. Few SCM or BSM that develop from eggs laid early in the season overwinter (with little variation). When eggs are laid in June to August, the proportion of SCM or BSM overwintering increases (with much variation). Most SCM or BSM that develop from eggs laid after August overwinter (with little variation).

Emergence of SCM adults from overwintered pupae was reported to occur in one discrete peak in May (Miller and McClanahan 1960, Nair and McEwen 1975, Funderburk et al. 1983). In the present study, $50 \%$ emergence of SCM did not occur until the middle of June, and flies emerged from overwintered pupae throughout the growing season. Protracted emergence from overwintering pupae also has been reported in some populations of the cabbage maggot (Finch and Collier 1983). Also, in the present study, a small percentage of SCM and BSM emerged after two winters. Polymodal emergence has been reported in other insects (Waldbauer 1978).

There are usually four SCM flight peaks in New York State each year-one each in late May, midJune, mid-July, and August (unpublished data). The patterns of SCM emergence in the emergence traps in 1981 and 1982 indicate that all SCM comprising the May flight peak emerge from overwintered pupae. The large June flight peak is comprised of flies recently emerged from overwintered pupae and of offspring of the flies that emerged in late April and in May. Thus, the large size of the June peak may be due to its dual composition. The midJuly peak is comprised of offspring of the June emerging flies, and the August peak of offspring of the July flies. Most of the offspring of the August flies enter diapause.

\section{Acknowledgment}

We thank Stan Finch, George Schaefers, and Emmett Lampert for reviewing earlier versions of this manuscript. We also thank the anonymous reviewers for helpful comments.

\section{References Cited}

Brooks, A. R. 1951. Identification of the root maggots (Diptera: Anthomyiidae) attacking cruciferous garden crops in Canada, with notes on biology and control. Can. Entomol. 83: 109-120.

Eckenrode, C. J., and R. K. Chapman. 1971. Observations on cabbage maggot activity under field conditions. Ann. Entomol. Soc. Am. 64: 1226-1230.

1972. Seasonal adult cabbage maggot populations in the field in relation to thermal-unit accumulations. Ibid. 65: 151-156.

Eckenrode, C. J., E. V. Vea, and K. W. Stone. 1975 Population trends of onion maggots correlated with air thermal unit accumulations. Environ. Entomol 4: 785-789.

Finch, S., and R. H. Collier. 1983. Emergence of flies from overwintering cabbage root fly pupae. Ecol. Entomol. 8: 29-36.

Funderburk, J. E., L. G. Higley, and L. P. Pedigo. 1984. Seedcorn maggot (Diptera: Anthomyiidae) phenology in central lowa and examination of a thermal-unit system to predict development under field conditions. Environ. Entomol. 13: 105-109.

Funderburk, J. E., L. P. Pedigo, and E. C. Berry. 1983. Seedcorn maggot (Diptera: Anthomyiidae) emergence in conventional and reduced-tillage soybean systems in Iowa. J. Econ. Entomol. 76: 131134.

Harris, C. R., H. J. Svec, and J. A. Begg. 1966. Mass rearing of root maggots under controlled environmental conditions: seed-corn maggot, Hylemya cilicrura; bean seed fly, H. liturata; Euxesta notata; and Chaetopsis sp. Ibid. 59: 407-410.

Harukawa, C., R. Takato, and S. Kumashiro. 1934. Studies on the seed-corn maggot. IV. Ber. Ohara Inst. Landwirtsch. Forsch. Kurashiki 6: 219-253.

Huckett, H. C. 1971. The Anthomyiidae of California exclusive of the subfamily Scatophaginae (Diptera). Bull. Calif. Insect Surv. No. 12.

Masaki, S. 1980. Summer diapause. Annu. Rev. Entomol. 25: 1-25.

Miller, L. A., and R. J. McClanahan. 1960. Lifehistory of the seed-corn maggot, Hylemya cilicrura (Rond.) and of $H$. liturata (Mg.) (Diptera: Anthomyiidae) in southwestern Ontario. Can. Entomol. 92 210-221.

Nair, K. S. S., and F. L. MeEwen. 1975. Ecology of the cabbage maggot, Hylemya brassicae (Diptera: 
Anthomyiidae), in rutabaga in southwestern Ontario, with some observations on other root maggots. Ibid 107: 343-354.

Ristich, S. S. 1950. Biology of the seed-corn maggot Hylemya cilicrura (Rondani) and preliminary studies on its control. Ph.D. dissertation, Cornell University, Ithaca, N.Y.

Strong, F. E., and J. W. Apple. 1958. Studies on the thermal constants and seasonal occurrence of the seedcorn maggot in Wisconsin. J. Econ. Entomol. 51: 704707.

Throne, J. E. 1980. Bibliography of the seed maggots Hylemya platura and $H$. florilega (Diptera: Anthomyiidae). N.Y. State Agric. Exp. Stn. Spec. Rep. No. 37

1983. A computer model for simulation of seedcorn maggot development. Ph.D. dissertation, Cornell Univ., Ithaca, N.Y.

Throne, J. E., P. S. Robbins, and C. J. Eckenrode. 1984. An improved screen cone trap for monitor- ing activity of flying insects. N.Y. Food Life Sci. Bull. No. 106.

Vea, E. V., and C. J. Eckenrode. 1976. Seed maggot injury on surviving bean seedlings influences yield. J. Econ. Entomol. 69: 545-547.

Vea, E. V., D. R. Webb, and C. J. Eckenrode. 1975. Seedcorn maggot injury. N.Y. Food Life Sci. Bull. No. 55.

Waldbauer, G. P. 1978. Phenological adaptation and the polymodal emergence patterns of insects, pp. 127144. In H. Dingle [ed.], Evolution of insect migration and diapause. Springer-Verlag. New York.

Yatom, S. 1961. Laboratory studies on the bionomics of Hylemya cilicrura Rond. in Isreal. Isr. J. Agric. Res. 11: 51-56.

Received for publication 10 July 1984; accepted 26 December 1984. 